Recorded number of total individuals was 592 belong to 90 species, 55 genera and 26 families. It includes 58 endemic species with 3 endemic genera (Loxococcus -1 sp., Shumacheria - 1 sp., Stemonoporus - $6 \mathrm{sp}$.). A total of 58 (250 individuals), 32 (174 individuals) and 29 ( 168 individuals) tree species were identified from lowland, sub-montane and upper montane forest formations, respectively. Identified species distributed in 3 forest formations as follows, lowland 43, upper montane 13, submontane 11, lowland and sub-montane 8 , lowland and upper montane 2, sub-montane and upper montane 8 , all three formations 5 . There were 35 endemic tree species in lowland $(60.3 \%), 22(68.7$ $\%)$ in sub-montane and $17(60.7 \%)$ in upper montane forest formations.

According to the IVI values, in the lowland forest formation Dipterocarpaceae was the dominant family, Myristica was the dominant genus and Myristica dactyloides was the dominant species. In the submontane and montane forest formations Palaquium rubiginosum was the dominant species.

The diversity index (Shannon's) was calculated for each plot and three different forest formations. These results were analyzed using analysis of variance. It showed that there were significant differences between lowland - montane lowland - sub montane formations. Same result showed for evenness and dominance.

\title{
108 \\ Pteridopytic diversity in Loolkandura forest
}

\author{
S R W A B M R JKandapola ${ }^{2}$, R G H Ranil', D K N G Pushpakumara' and T Sivananthawarl' \\ 1 Department of Crop Science, University of Peradeniya, Sri Lanka \\ ${ }^{2}$ Postgraduate Institute of Agriculture, University of Peradeniya, Sri Lanka
}

The plant category ferns and fern allies are taxonomically known as Pteridophytes. In Sri Lanka about 340 Pteridophytes have been recorded belongs to 29 families. They have ornamental, medicinal and edible values and play an important role in biodiversity of forest understory. Unlike flowering plants, studies on Pteridophytes are limited in Sri Lanka. Sri Lanka's first tea plantation has started in Loolkandura area but the remaining hilly areas still exists as undisturbed forests with high biodiversity. However limited studies have been carried out on biodiversity of Loolkandura forest area. Consequently, the objective of this study was identification of Pteridophytic diversity of Loolkandura forest area.

Three elevation levels $(1100,1300$ and $1500 \mathrm{~m})$ were selected along the stream networks and three plots (each of $10 \times 10 \mathrm{~m}$ ) from each elevation level were established for sampling. Number of species, their population size and habitats were assessed for each plot. Data were analyzed to identify correlation of species and individuals with elevation levels. A total of 56 Pteridophytes from 19 families were identified from studied area. Seventeen percent of Sri Lankan Pteridophytic flora represent in Loolkandura forest area which consists 3 endemic species (Cyathea walkerae, Meringium macroglossum and Diplazium beddomei). Two main Pteridophytic habitats were identified as lithophytes and terrestrial (terrestrial dense forest, terrestrial open and terrestrial road side). In Loolkandura forest area, both number of families and number of species are in increasing trend with increasing of elevation. There are three species namely, Asplenium nomale $\left(\mathrm{R}^{2}=0.69\right)$, Metathelypteris flassida $\left(\mathrm{R}^{2}=0.54\right)$ and Polystichum biaristatum $\left(\mathrm{R}^{2}=0.64\right)$ showed significantly positive relationship with number of individual of a species with increasing of elevation from 1100 to $1500 \mathrm{~m}$. Two species namely Arachniodes aristata $\left(\mathrm{R}^{2}=0.69\right)$ and Tectaria decurrence $\left(\mathrm{R}^{2}=0.59\right)$ showed decreasing trend in number of individuals with increasing of elevation. Disturbances to the ecosystem and soil moisture content were identified as major parameters to variations of Metathelypteris flassida and Arachniodes aristata. Checklist for Pteridophytes was prepared for the studied area and implications of findings on conservation and utilization of Pteridophytes are discussed.

Proceedings of the International Forestry and Environment Symposium 2006 of the

Department of Forestry and Environmental Science. University of Sri Jayewardenepura. Sri Lanka 